\title{
Clinical Trial Filenotes Master List
}

National Cancer Institute

\section{Source}

National Cancer Institute. Clinical Trial Filenotes Master List. NCI Thesaurus. Code

C115531.

A directory of all file notes generated during a clinical trial. 